\title{
Rare Earth Elements Resources and Different Recovery Techniques from Egyptian Ores
}

\author{
Hesham M Kamal* \\ Nuclear Materials Authority, Cairo, Egypt
}

Received: November 16, 2017; Published: November 29, 2017

*Corresponding author: Hesham M Kamal, Nuclear Materials Authority, El Maadi, Cairo, Egypt, Tel: 2027585835; Email: heshgeo10@hotmail.com

Abbreviations: ESM: Electron Scanning Microscope; PG: Phospho Gypsum; MIBK: Methyl Iso-Butyl Ketone; TOA: Tri-Octyl Amine

\section{Introduction}

In fact, bastnaesite, monazite and xenotime are the most important rare earth-bearing minerals known as sources for extraction of rare earths by hydrometallurgical approaches to produce intermediate products in the form of rare earth-chlorides, fluorides, halides, and oxides. In the following paragraphs I will summarize some of the rare earth elements extraction using variety of their extraction techniques from some treated Egyptian ores. Leachability of lanthanides from the radioactive pegmatite pockets found in Gabal Abu Furad area, southwest Safaga city, limited by latitudes $26^{\circ} 37^{\prime}$ and $26^{\circ} 43^{\prime}$ and longitudes $33^{\circ} 36^{\prime}$ and $33^{\circ} 43^{\prime} \mathrm{E}$. Central Eastern Desert, Egypt. It was investigated using different acids at different concentrations, liquid-to-solid ratios, contact times and temperatures in order to determine the optimum recovery conditions. The best leaching efficiency was obtained with $40 \mathrm{~g} / \mathrm{l} \mathrm{HCl}$ solution; $8 \mathrm{hrs}$ contact time, $90^{\circ} \mathrm{C}$ temperature and $1: 5$ (g/ml) solid: liquid ratio. Afterwards, lanthanide stock solutions were prepared by applying the optimum leaching conditions. Lanthanides were then precipitated by either $10 \%$ oxalic acid or $20 \%$ sodium hydroxide solutions. Electron scanning microscope (ESM) analysis was utilized to determine the qualitative percentage of the existed lanthanides. It was found that thorium percentage was around $10.05 \%$. High percentages of light lanthanides were detected, e.g., La (11.16\%), cerium (39.97\%), Pr (6.21\%), Nd (13.99\%), Sm (2.00\%), and Gd (1.06\%) [1].



Figure 1: Geologic map of Gabal Abu Furad, Central Eastern Desert, Egypt (modified after Mahmoud, 1995 - Dardier and El Wakeel 1998).

The study area of El-Garra El-Hamra is one of the igneous masses located in the southern part of the Western Desert of Egypt. This work has been carried out to investigate the process of gadolinium separation from REEs cake obtained from El-Garra El-Hamra ore concentrate. It is considered as a new approach in the Nuclear Materials Authority of Egypt. Firstly, the optimum leaching 
conditions achieved are $200 \mathrm{gm} / \mathrm{L} \mathrm{H}_{2} \mathrm{SO}_{4}, 1 / 2$ solid/liquid ratio, 4 hours agitation time, 125 mesh size and at $900 \mathrm{C}$ temperature. Then by solvent extraction method using 1mol/L D2EHPA middle REEs were extracted (Figures $1 \& 2$ ). The organic extractant was stripped by using $2 \mathrm{~mol} / \mathrm{L} \mathrm{HCl}$ and $\mathrm{Gd}$ pregnant solution was obtained. Then, the relevant optimum factors were $0.3 \mathrm{~mol} / \mathrm{L}$ D2EHPA diluted by kerosene, 10 minutes contact time, and $4 / 1$ organic/aqueous ratio giving $87 \% \mathrm{Gd}$ extraction. Then, the scrubbing of the loaded extractant was by $1 \mathrm{~mol} / \mathrm{L}$ HCL followed by Gd stripping using $5 \mathrm{M}$ $\mathrm{HCl}$, contact time of $30 \mathrm{~min}$. and $1 / 3$ organic/aqueous ratio. The strip solution was subjected to evaporation and little amount was dried to obtain $\mathrm{GdCl} 3$ powder having a purity of about $81 \%$ associated with YCl3 4\% [2].

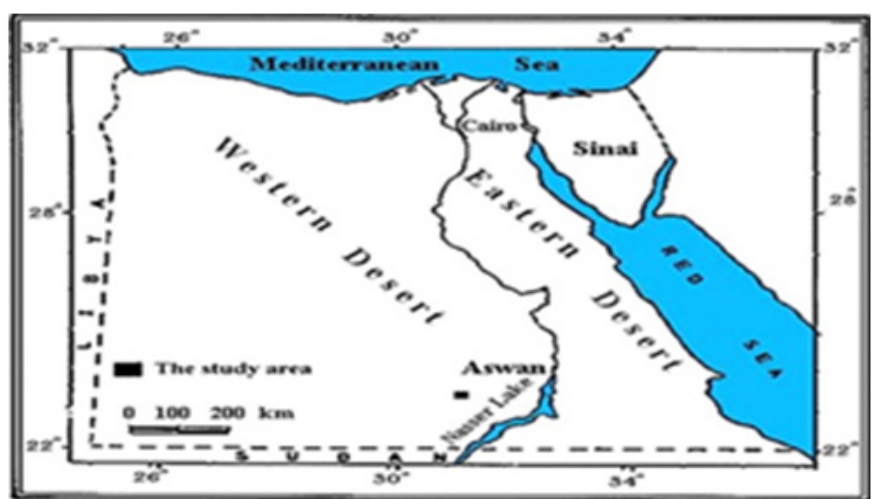

Figure 2: Map of Egypt showing location of the study area.

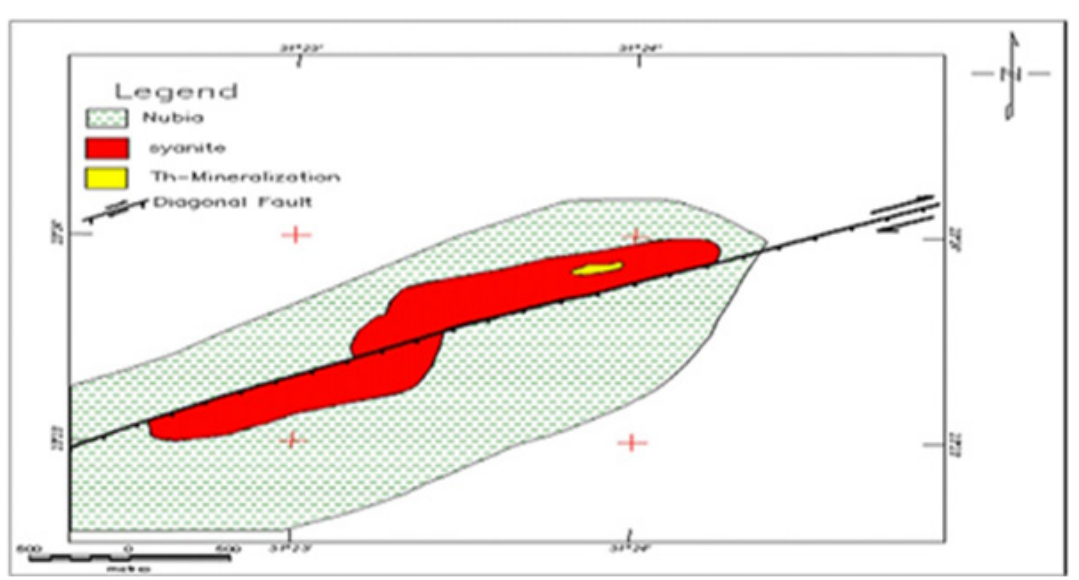

Figure 3: The Geographical map of EI-Hamra area, South western Desert Egypt.

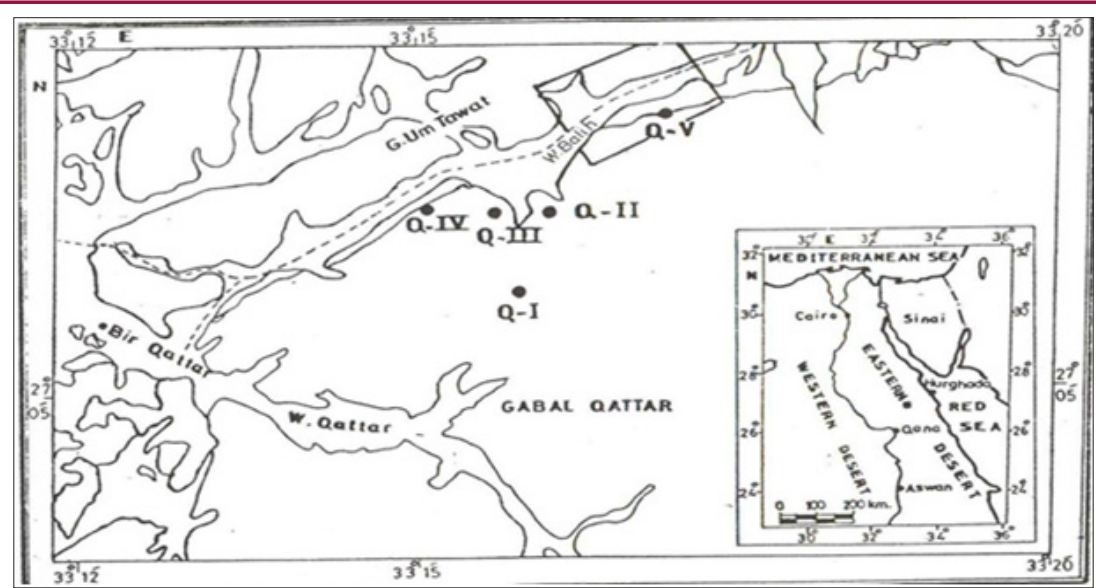

Figure 4: Location map of Qattar and prospect area Gabal Qattar, Northern Eastern desert, Egypt.

The study area of El-Garra El-Hamra is one of the igneous masses located in the southern part of the Western Desert of Egypt. In this study, it is emphasized upon the Y extraction because as far as the author is aware, it is the first time to prepare $\mathrm{Y}$ concentrate from the local ores. Thus, the prepared sample is enriched in $\mathrm{U}, \mathrm{Th}, \mathrm{REE}$ and $\mathrm{Y}$ and hence it is suitable for such study. In the $\mathrm{Y}$ extraction process the REE cake would first be dissolved in $8 \mathrm{~N}$ HNO3 and then contacted by the organic solvent TBP $(100 \% \mathrm{v} / \mathrm{v}$ 
for $15 \mathrm{~min}$. while using an 0/A ratio of 1:1). By applying the counter current solvent extraction system, it is expected that 2 stages are sufficient to achieve almost complete Y extraction. Scrubbing step would be performed upon the loaded solvent to remove most of the undesired elements (Figure $3 \& 4$ ). This is done by using distilled water for 2cycles. Y loaded TBP solution would then be subjected to the stripping step by $6 \mathrm{~N} \mathrm{H}_{2} \mathrm{SO}_{4}$ acids when using A/O ratio of $1: 2$ for $60 \mathrm{~min}$. Also, it is expected that 5 stripping stages are sufficient to strip out most of the Y content while the depleted TBP will be recycled to the regeneration tank. Y could be precipitated by adjusting the stripped solution at $\mathrm{pH} 7$ by using ammonia solution and then by adding $12 \%$ oxalic acid drop by drop during stirring until almost complete precipitation of $\mathrm{Y}$.

The obtained $\mathrm{Y}$ oxalate was then claimed at 5500C for 2hours to obtain yttrium oxide $\mathrm{Y}_{2} \mathrm{O}_{3}$ [3]. Phosphogypsum (PG), a residue of the phosphate fertilizer industry that has relatively harmful concentrations of rare earth elements (as lanthanides) is accumulated in large stockpiles and occupies vast areas of land. The present work was oriented to decrease the concentration of lanthanides by leaching of PG using the synergism of methyl iso-butyl ketone (MIBK) and Tri-octyl amine (TOA) in kerosene modified by 1-octanol. The factors which affect the leaching process such as agitation time, concentration of the solvent, liquid/solid ratio, and temperature were optimized. Based on the experimental results, about $92.1 \%$ of lanthanides were successfully transferred from the PG into the solvent phase. Nitric acid has been used to strip the lanthanides from the organic solvent. The precipitation of 93.4\% of lanthanides was carried out using oxalic acid under the desirable conditions. A decontaminated product that can be safely used in many industrial applications was obtained [4].

Gebel Gattar area is considered one of the most promising uranium mineralization occurrence located in the northern Eastern
Desert of Egypt, located at the intersection of latitude 270 7/ 30// N and longitude 330 17/ 5// E covering about $2 \mathrm{~km} 2$. Hydro thermal alterations of Gabal Gattar granitic mass at GII occurrence exhibited an increase in $\mathrm{Ni}, \mathrm{Cu}, \mathrm{Zn}, \mathrm{Pb}, \mathrm{Mo}, \mathrm{Nb}$, Rb beside HREEs. A technological sample from GII occurrence was subjected to extraction of REEs through both leaching and precipitation processes. The optimum leaching conditions achieved were as follows: $40 \mathrm{~g} / \mathrm{l} \mathrm{HNO}_{3}$ acid, 12 hours contact time, 1/2 S/L ore/acid ratio, 60 mesh grain size and room temperature (250C) giving REEs leaching efficiency of about 97\%. REEs were directly precipitated using sodium hydroxide (20\%) where REEs hydroxide was obtained at pH 8.5 [5]. The above text through a light on some applications of extracting rare earth elements performed in my dear country Egypt, I hope it may be benefit for the interested readers.

\section{References}

1. Kandil AT, El Nagar WE, Kamal HM, Younes AA, Mossa HH (2017) Leachability of Lanthanides from their Bearing Rocks at Abu Furad Area, Central Eastern Desert, Egypt Research \& Reviews. Journal of Chemistry J CHEM 6(1).

2. Hesham M Kamal, Khalid F Mahmoud, Mohamed R Shehata (2014) Extraction of gadolinium from El-Garra El-Hamra rare-earth cake, SouthWestern Desert, Egypt. Journal of Radio analytical and Nuclear Chemistry 299(3): 1231-1240.

3. Mahdy MA, El Dougdoug A, Kamal HM (2017) Extraction of U, Th, Y and REE from El Garra El Hamra ore concentrate. The $19^{\text {th }}$ International Mining Petroleum and Metallurgical Engineering Conference. Cairo University, Egypt.

4. Hesham M Kamal, Mohamed M Fawzy (2016) Recovery of Lanthanides Cake from Industrial Phosphogypsum Waste. American Journal of Science and Technology 2(6): 335-345.

5. Hesham M Kamal (2016) Leaching Study of Lanthanides from its Mineralized Rocks at Gebel Gattar, Eastern Desert. International Journal of Research in Engineering and Science (IJRES) ISSN 4(6): 1-10.

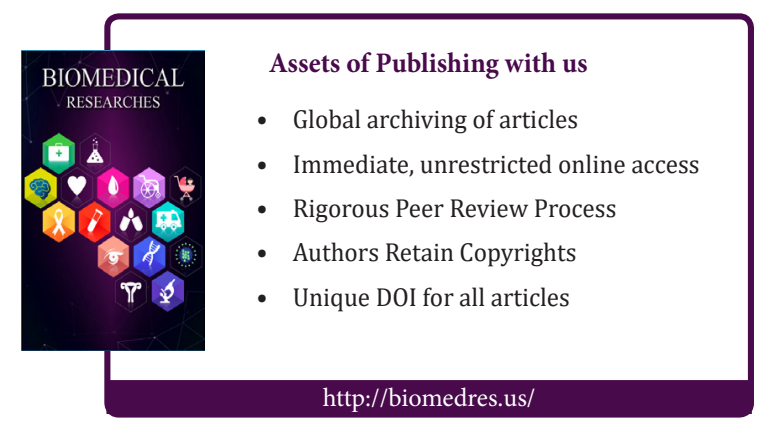

